American Journal of Applied Sciences 8 (11): 1182-1194, 2011

ISSN 1546-9239

(C) 2011 Science Publications

\title{
Sustainability of International Standards Organisation 14001 Standards through Integration with Lean Principles
}

\author{
Puvanasvaran, A.L., Perumal, Robert Kerk Swee Tian and Mohd Razali Muhamad \\ Faculty of Manufacturing Engineering, University Technical, \\ Karung Berkunci 1200, Ayer Keroh, 75450, Melaka, Malaysia
}

\begin{abstract}
Problem statement: Both Lean and Environmental Management System (EMS) are key business processes which are employed by companies to enhance their manufacturing process and quality performance. ISO 14001 requires a commitment to continual improvement. Yet it does not prescribe how a company should seek the continual improvement. Lean is a process improvement method that helps companies that use it to continually improve. This study analyses these two systems and provides an understanding of how these processes had contributed in improving business efficiencies. Approach: The research methodology applied in the context of this study involved both primary and secondary research methods in gaining a deeper and practical insight into the issues facing Lean and EMS integration. The primary data collection process involved the use of questionnaires for the purpose of gaining a practical insight into the research issue. The literature review summarized the evidence collected from various secondary sources to enable an understanding of the scope, benefits and application of Lean and EMS systems. Results: The findings contributed to the framing of new conceptual framework that combines benefits of both Lean and EMS principles for enhanced business results. Conclusion: This study concluded that an integrated business model can help organisations realize potential benefits and possibilities in the field of business enhancement.
\end{abstract}

Key words: International Standards Organisation (ISO) 14001, lean principles, sustainability, integrating model, EMS principles, production costs, environment-friendly production method, business efficiency, business models

\section{INTRODUCTION}

Management practices in the recent days have undergone rapid transformations owing to global changes taking place. The focus of organisations have been on increasing operational efficiency, reducing costs, enhancing quality levels, ensuring steady profits and meeting customer needs. The efforts of the management in the recent times have been on enhancing productivity through efficient methods of production that emphasizes on the elimination of unnecessary procedures and processes that add to production costs. The efficiency of production process is determined by the optimal use of resources and by adopting an environment-friendly production method. Environment management systems or EMS has been the focal point of managerial strategies in most organisations today. EMS has been defined by Kolk and cited in OECD (2001) report, as "a part of the overall management systems which includes the organisational structure, responsibilities, practices, procedures, processes and resources for determining and implementing the firm's overall aims as well as principles of action with respect to the environment."

EMS practices within an organisation needs to be integrated with existing organisational practices to realize its true potentials. Research studies have revealed that majority of organisations focus more on gaining market competitive advantage, improving customer relations and increasing profit potentials than adopting work processes that satisfy environmental safety and policy requirements. The significance of implementing such practices within an organisation is evident in the growing environmental concerns as a result of globalization of economies that in turn will yield a corresponding increased production of goods and services. Organisations have to re-engineer their business strategies to comply with environmental regulations laid down by legislative authorities in the interest of social surroundings.

The implementation of EMS practices within an organisation takes shape in different forms of strategic

Corresponding Author: Puvanasvaran, A.P. , Faculty of Manufacturing Engineering, University Technical,

Karung Berkunci 1200, Ayer Keroh, 75450, Melaka, Malaysia 
moves and processes that involves the use of total quality management principles and standards such as ISO 9001. Lean is one such business model that focuses on delivering quality products to the customer at reduced cost of production. The principles of Lean are founded on understanding of customer needs and demands, eliminating non-value added activities from the production process, involving the workforce in resolving operational issues, define metrics for measuring organisational performance, assist in decision making process and problem solving (RAESL, 2004). The essential difference between conventional production processes and Lean model lies in fact that while conventional production processes focused on the product, Lean emphasizes the customer needs and expectations as the guiding factor (RAESL, 2004).

Purpose and objective of research: The application of EMS and Lean within firms can help in overcoming operational challenges and improving business efficiency. Both systems are different in scope and approach but integrating the systems can help organisations achieve excellence in business performance and meet EMS objectives. The researcher proposes that organisational work processes can be effectively streamlined for improved efficiency and performance through adopting an integrated system that combines the benefits of both EMS and Lean. The research study provides an insight into the various aspects of EMS and Lean practices within the organisation and how it can be integrated to enable organisations to improve business efficiency. The objective of the research study hence is to identify the scope of integrating EMS and Lean systems to enable firms in achieving greater degree of business efficiency.

Scope of research: The scope of the research is limited to defining and analysing the systems and application of EMS and Lean within any organisation. The study explores the various aspects and dimensions of EMS and Lean systems, their approach and impacts on organisational performance, efficiency and productivity with the objective of finding the possibilities of integrating both for enhanced performance within firms. The research focuses on providing an understanding of the conceptual framework behind the two systems and its application within the organisational environment. This involves the study of why ISO 14001 is not sustainable, what measures can be taken to make it more sustainable and what are the prospects of integrating Lean with EMS systems. Based on the findings of the research the study will provide recommendations on effective practices and system implementation issues that can help organisations in creating a sustainable business model.

Research contribution: Organisations over the past few decades have focused on applying the principles of Lean and EMS for a sustainable development and optimising their production resources. The primary objectives behind the application of such standards are both cost savings and environment considerations. However, the implementation of an integrated model is not easy in view of the challenges faced by the organisations. The business models developed along the lines of these principles are guided by the need for continual improvement in production processes. Considering the challenges posed by the rapid changes within the business environment the research study contributes to the development of a new framework that helps the firms in complying with the needs of sustainable growth and development objectives.

\section{MATERIALS AND METHODS}

Literature review: The literature review will focus on identifying the various aspects of Lean and EMS systems, ISO 14001 standards and its prospective business applications.

In the 21 st century, there is great emphasis on companies and businesses to contribute towards protecting the environment as part of their corporate social responsibilities. Companies need to adopt measures to protect and enhance the environment in order to maintain good relations with customers, suppliers and vendors. There is a growing need for businesses to fulfil their corporate social responsibilities in order to survive in the global economy. Environment Management System or EMS can help the company in fulfilling their responsibilities towards protecting the world environment (Gbedemah, 2004). An EMS provides the framework to manage the company's environmental responsibilities effectively and also helps in integrating the environmental initiatives into the day-to-day operations. An efficient EMS is critical to all types of business irrespective of the nature, size and scale of operations. In the global market, it is important for manufacturing, automobile, retail and service industries to have an EMS in place. An effective EMS contributes to cost savings and reduces the environmental liabilities (Cheremisinoff et al., 2009). A company that has a good EMS in place will be able to satisfy the needs of suppliers, customers, employees, investors, regulatory bodies and environmental groups. This will help in boosting the image and reputation of the company in the marketplace. An EMS is defined as 
part of the management system in which the objectives, plans, policies and procedures relating to its environmental responsibilities are defined. It provides a basis for identifying, evaluating, managing and sustaining the company's contribution towards the environment. EMS ensures that the measures taken towards environmental protection are implemented in the organisation and that the company meets its environmental goals. It also helps in ensuring that employees, suppliers and vendors understand their role in the environmental policy and contribute effectively towards meeting the environmental objectives of the organisation (Visser et al., 2010).

ISO 14001 is an internationally accepted standard that sets out the steps to be taken by a business to put in place an effective EMS (EPA, 2002). It helps in integrating the environmental goals into the overall operations of the company. The ISO 14001 standards were written with the consensus of nearly 50 countries and more than 100 countries have endorsed it as an international standard. ISO 14001 is applicable to all types of organisations with varying nature and size of operations. It is also relevant to companies with different risk profiles and is easily adaptable either to an entire organisation or a specific function (Woodside and Aurrichio, 2000). The International Standards Organisation (ISO) first published ISO 14001 in 1996. Since then, organisations worldwide have implanted the standard in their operations. There could be various reasons for a company to implement ISO 14001. It helps in promoting a green corporate image and also boosts market share. ISO 14001 helps in (a) minimizing waste and thus reduces the costs involved in managing waste, (b) reducing insurance and prosecution risks and (c) gaining investor confidence and bringing in more ethical investment (Whitelaw, 2004).

ISO 14001 is a series of standards used in environmental audits. It outlines an approach focused on processes for efficient environmental management. It can be applied in any organisation irrespective of the size and nature of operations. ISO 14001 mainly involves internal audits and does not include performance goals. Although ISO 14001 has not been designed specifically for sustainability, it can monitor a number of environment issues and offer a potential platform for sustainability assessment. Few organisations hire consultants to perform the sustainability audits. These consultants offer sustainability audits as a service and conduct an inspection of the carbon footprint of the organisation. They ensure that sustainability policies, procedures and programs are properly implemented throughout the company (Collin and Collin, 2009). Companies that have worked on improving sustainability are at the forefront of environmental regulation. According to Collin and Collin (2009), "The scope of environmentally regulated activities will expand under sustainability to areas of society other than big industry. It will spread to reach smaller industries and then municipal emissions, military emissions and wastes and other waste streams that impact the environment. Knowledge of the environmental impacts of development provides much of the impetus toward sustainability." ISO 14001 provides the framework including the guidelines and standards for an effective and efficient EMS that can be applied to industries irrespective of the nature, size and risk profile (Gbedemah, 2004). These standards provide a platform for internal and external audits. It can used effectively to measure the environmental performance of the company and improve its internal processes for continual improvement. A business can also engage a third party firm that performs audits on the basis of the ISO guidelines and certify its systems and processes (Sedjo et al., 1998).

Sustainable business development is one of the primary considerations driving business strategies and operational frameworks. Sustainable development goals involve increased awareness of organisational impact on environment, "acceptance of responsibility of these impacts, expectation that harmful impacts will be reduced or eliminated and the placement of responsibility for environmental impacts upon all members of the community" (Haklik, 2002). The ISO 14001 standards were developed in view of these needs for building a sustainable business environment. ISO 14001 acknowledges that not all environmental aspects affecting an organisation may be in its control. There could be aspects of the environment which the business does not have any influence on. As a result, ISO 14001 requires that a company defines and regulates only those aspects of the environment that it can exert an influence on and control. A business establishing its EMS should look at only those environmental aspects which it can control. The firm's environmental policy should be designed accordingly Federal Environment Executive 2002. ISO 14001 aims at continuous improvement in the environmental performance of a business to bring about a positive impact on the overall environment in which the company functions (Hancock, 2005). The ISO standard consists of five important steps: designing the environmental policy, planning, implementation and operation, checking and corrective action and management review. Once the standard is implemented in the organisation, it creates a self-sustaining cycle that focuses on continuous 
improvement and helps the company reach its environmental targets (Lesourd and Schilizzi, 2001). In designing the environmental policy, the company must ensure that it suits the requirements and is relevant to its products and services. The next step is to identify the environmental aspects which it can control and include those aspects in the policy. The company should ensure that its environmental policy conforms to legal requirements. The next step for the business is to establish the environmental goals and objectives. It should lay out the measures through which these goals can be accomplished. The environmental policy should define the roles and responsibilities of each element in the EMS (Cragg, 2005). It is very important to involve employees at all levels in the organisation in implementing ISO 14001 standards. EMS can succeed and bring about a positive impact on the environment only with the active participation of employees across various functions and levels. The company must also aim at improving the communication between employees and external parties for effective collaboration. It must schedule periodic and regular audits in order to ensure that the performance is sustained and consistent over a period of time. Another crucial aspect is reviewing the EMS by the senior management to ensure that the performance is measured at regular intervals. This helps in checking if the environmental targets are being met. Suggestions for improvement must be considered. In case there are deviations in the performance from the set targets, suitable measures need to be undertaken. This management review helps in bringing about continuous improvement in the EMS (Parto and Herbert-Copley, 2007). Strong management support is a critical success factor for the EMS to work effectively in an organisation. ISO 14001 understands this aspect and outlines that it is the responsibility of senior management to formulate the environmental policy of the organisation. Only when the standards and measures are fully backed by the senior management, implementation can be done smoothly across all the functions (Woodside and Aurrichio, 2000). In this era of globalization, there is a great thrust on companies to work towards attaining sustainability in their operations. There is a need for companies to monitor their carbon footprint in the world and have a positive impact on the environment. Companies that contribute towards sustaining and enriching the environment have a good corporate image. They can maintain mutually productive and long-standing relationships with employees, customers, suppliers and vendors by implementing an effective EMS that conforms to ISO 14001 standards (Wilson and Sasseville, 1998). Such businesses are also able to attract more investors as they will be perceived as fulfilling their corporate social responsibilities.

Lean is a tool for process improvement that aims at maximizing customer value and minimizing waste (Miller et al., 2010). Lean helps in focusing on key processes that affect the output to the customer. It focuses on continuously improving the process management elements to deliver maximum value to customers. Lean helps in achieving the organisational goals with fewer resources and zero waste. Lean does not focus individually on systems, tools, technologies, assets and functions. It works at optimising the process flow across assets, systems, technologies and functions to deliver the best value to customers (LEI, 2009a). Earlier, Lean principles were thought to be relevant only to manufacturing companies. This is no longer true. Lean can be implemented successfully across all industries. For an organisation implementing Lean, it is enough to just adopt a few principles only for certain processes. This will not have an impact on the performance of the company. To reap the full benefits of Lean, the company must adopt it as part of their business strategy (Turbide, 2005). This will result in Lean principles being implemented consistently across all the functions in the organisation and will have a positive impact on the overall performance. Lean should be adopted as a way of thinking and as a way of doing business in order to fully enjoy its benefits (Sarkar, 2008). Lean methodology is focused on minimizing waste in the organisation's value streams and reducing costs. When Lean principles and methodology are implemented strategically, the organisation can adopt Lean across functions. According to Reidenbach and Goeke (2006), "Rather than having cost reduction as the exclusive focus of Lean thinking, the conceptual framework of Lean also has tremendous potential for increasing top-line revenue by creating a sustainable differential value advantage for the enterprise that deploys the concept in its entirety."

Lean is a tool of process improvement that aims at eliminating waste and creating maximum value for the customer. It focuses on optimising the process flow across the organisation in order to deliver the best quality product or service to the client using minimum resources at zero waste. The five principles of Lean are: identify value, map the value stream, create flow, establish pull and seek perfection (Murman, 2002). The first step is defining the value from the viewpoint of the customer. The second step is to identify the key elements in each process across different product and 
services that the company offers. The main aim of this step is to eliminate those processes that do not create any value. The next step is to focus on those steps that create value and bind them in a cohesive sequence so that the supply chain is optimised. This will ensure that the product/service is delivered to the end customer in an efficient manner without any delays. In the fourth step, customers pull value from the next activity in the integrated value stream. In the final step, the company must aim at perfecting the process flow and bringing the value of wastage to zero. Once the Lean principles are implemented in the organisation, value streams are identified and wastage is minimized. This creates a self-sustaining cycle where there is continuous improvement in the process flow and zero wastage (LEI, 2009b).

Earlier it was thought that Lean and EMS have different objectives and hence cannot be integrated. A company would implement its Lean and EMS initiatives separately with a view that the two target different kind of waste. Lean involves implementation of measures for optimising the process flow and minimizing waste. EMS is aimed at putting policies and procedures in place to reduce the adverse effect on the environment. Subsequently, studies have shown the strong relationship between the Lean and green activities in an organisation. Both Lean and green initiatives share a common goal of reducing wastage. The wastage defined in Lean management also has significant environment impact. Implementation of Lean principles will have a positive impact on the company's environmental performance. As a result, many authors and government policy makers advocate the implementation of Lean tools and systems in managing the environment. A business should take a holistic approach in implementing EMS and integrate the Lean principles to the environmental aspects of the company. Companies should work towards fostering an effective relationship between the Lean and green activities to maximize customer satisfaction and minimize waste (Mitsuishi et al., 2008).

For the Lean principles to be integrated into the ISO 14001 standards in an organisation, the environment policy and Lean objectives must be clearly defined. A well defined system must be in place setting out the roles and responsibilities of the employees in different departments across various levels. The employees should clearly know what their Lean and green goals are and the means to achieve them. This helps in reducing the time and effort spent on searching for solutions (Gordon, 2001).
Studies show that in existence of environment management systems in organisations help in promoting Lean management as both target cost and waste reduction. There is also evidence that there is a need for stronger co-ordination and collaboration between the Lean and environment management activities. There could be a conflict amongst the goals set for the Lean and green efforts. This has to be addressed at the strategic level by the senior management. They should roll out the agenda for the Lean and green initiatives that ensure that the goals can be achieved in a co-operative and seamless environment. Employees must be made aware of the advantages in using the Lean principles in environment management. They must understand the importance of combining and working on Lean and green efforts simultaneously.

The process of integrating Lean into the EMS is a multi-layered process and involves many steps. The first step is listing those areas of function in the company which has the largest environmental impact. The business should ensure that the Lean principles are integrated into those processes that impact the environmental performance. The next step is creating awareness amongst the employees about the Lean and green efforts of the company. Employees must be made to feel that their company does really care about the environment and not merely undertaking to implement EMS for ISO certification. They must be able to see and understand the vision of the company in integrating Lean principles into ISO 14001 standards. Employees must be fully aware of the course of their actions and their environmental impact. It is only with this understanding that organisations can get the full support and participation of the employees in integrating Lean principles into the EMS (Gordon, 2001).

The company should work on integrating the EMS requirements into the existing systems. If a separate process flow is created for EMS, there could be issues of lack of coordination between the environmental measures and other processes. As a result, it is important for organisations to integrate the Lean and green efforts into its day-to-day operations. The environmental control should be decentralized in the organisation. Each function or department must have environmental goals as part of their operational agenda. This means that there will be efforts made towards positive environmental impact from all parts of the organisation. In communicating the ISO 14001 standards to the employees, it is very crucial to use simple language to enable understanding at all levels. It is only when employees understand what the ISO 14001 standards necessitating will they be able to implement in their routine functioning. There should be 
cross functional interaction and cooperation in integrating Lean and green efforts. The company should encourage collaboration between offices at different locations in implementing ISO 14001. Different offices can help one another in integrating Lean principles into ISO 14001. Best practices followed by each unit in implementing EMS can be put together and be communicated on a company level.

Training the employees on EMS and ISO 14001 should be according to the company's culture. Through training initiatives, the employees should be able to understand that their behaviour and attitudes affect the environment. They will be motivated to take initiatives in achieving the environmental goals and contribute to the organisation. If there is a requirement, companies can also engage third party trainers and consultants to gain knowledge on integrating Lean and green efforts (Gordon, 2001).

The United States Environmental Protection Agency (EPA) has acknowledged the benefits of integrating Lean and green activities. EPA encourages companies to recognize environmental waste as a form of waste and include it as part of the seven wastes identified in the Lean methodology. It recommends organisations to identify opportunities for improvement by including environmental, health and safety norms into value streams. EPA also recommends integrating the environmental metrics into the Lean metrics of each process. This ensures that when performance evaluation is done for each process, the efforts towards environmental goals can also be measured. In case there are any deviations in the actual performance from the targets set, suitable corrective action can be taken. Employees who have knowledge and are specialized in the fields of environment, health and safety must be given active roles in implementing Lean initiatives in the company. EPA encourages companies to use the Lean tools and technologies to identify and minimize environmental waste in the key process flows. Finally, employees must be given training to identify the environmental wastes in their process. They must be given the appropriate tools and systems to eliminate environmental waste in their areas of functioning (Russell and Taylor-lii, 2008).

The initiatives taken for integrating Lean principles into environment management must be adaptable to the organisation culture. Each company has a way of doing things. The environmental policies and procedures must be integrated into the existing operational system. It must not be intrusive to the process flow. It should be seamlessly included in the daily operations. The company must also study the economic and social environment of the country in which it is operating. The Lean and green efforts must be clued in to this environment. The initiatives should be rolled out according to the requirements of the specific region in which the company is operating (Gordon, 2001).

Summary of literature review: Lean principles encourage an organisation to bring about significant changes in their operational and cultural environment. This in turn has a positive impact on the environmental performance of the company reducing pollution, wastage and emissions. Lean principles enable companies to deliver with lesser resources resulting in lesser scrap and wastage. It encourages organisations to judiciously use natural resources, such as energy, water and forest products. Lean pushes for continuous improvement and empowers companies to better their environment performance.

It can be seen that Lean principles and ISO 14001 standards have a lot of common ground and both aim at reducing waste. Lean focuses on delivering the maximum value to the customer using the required resources at minimum waste. When an organisation implements Lean, there are significant cost savings. There is optimum utilization of resources and wastage is reduced. This has a positive impact on the environmental performance of the company. When a company is implementing Lean principles into EMS, it must clearly set forth the objectives of such an initiative (MacDonald, 2005). The senior management must play an important and visible role in implementing the Lean and green initiatives. The procedures and measures for attaining the goals must be clearly communicated to the employees at all levels. There must be cross functional cooperation in the organisation to learn and benefit from mutual experience. There should be a process for acknowledging the best practices of each unit and introducing the same at the company level. A company can benefit tremendously from combining the Lean and green efforts. The company will be seen as contributing to protecting the environment and preserving it for future generations. It will result in reduced cost of operations, optimum utilization of resources, reduction in wastage and better profitability for the organisation.

Research methodology: The research design is one of the key factors determining the effectiveness of the research study. If the research method applied does not meet the needs of the research objectives the findings and analysis of data collected is wasted. The selection of appropriate research method is based on an improved understanding of the research objectives and research 
questions that define the scope of study (Malhotra and Birks, 2007). The research method must enable the researchers to gain a broader perspective on the research issue and provide a supportive framework to the findings and solutions. This part provides an overview of the research methods adopted during the course of the study and the justification of adopting the chosen methods.

Any research study is guided by five principles of research design that include the identification of research goals and objectives, planning the conceptual framework to develop the research arguments, establishing the research questions, decide on the methods to be used for data and information collection and validating results for purpose of accuracy and relevance to the research context (Maxwell, 2005). The exploratory research study involved the use of qualitative research method for collection of vital data and information that contributed to the inferences from the findings.

The research method adopted for this study combines both primary and secondary data collection process. The findings and subsequent analysis of the research study is based on the primary and secondary data collection process. The choice of research method was based on the appropriateness of the research context that warranted a practical insight into the implementation issues and challenges facing the application of Lean and EMS within the organisation. This complemented the conceptual framework and analysis provided by the secondary research method. The research study on the effectiveness of Lean, EMS and effective integration of both systems within businesses needed an exploratory perspective that helped the researcher in using theoretical frameworks to explain and understand the significance of the systems and their scope of application. The primary and secondary data collection process contributed to the research study by enabling the researcher to highlight significant aspects related to Lean and EMS and analysing the possibility of expanding business performance and efficiency by integrating the two systems.

For the purpose of gaining an in-depth knowledge and understanding of key areas of focus and analysis the research process included extensive study of available literature, previous research study papers, journals, periodicals and information database. The information retrieval process included electronic search of existing database, journals, literary sources and research studies completed by other researchers on similar subject matters. The literature review summarized the evidence collected from various secondary sources to enable an understanding of the scope, benefits and application of Lean and EMS systems.

The primary data collection process involved the use of questionnaires for the purpose of gaining a practical insight into the research issue. The questionnaire followed a simple format using openended questions to enable the respondents to provide their views and experience on the research context. Open-ended questions are useful in eliciting a detailed response from the respondent and can be effective in gaining useful insights into the research study. The questionnaire was designed for the purpose of gaining an insight into the issues and challenges related to the implementation of Lean and EMS within the manufacturing and service industries. The sampling unit chosen for filling up the questionnaire constitutes of managers and executives in various industries. The participants were selected on a random basis. A total of 15 respondents were selected for the sampling unit. The limited size of the sampling unit was on account of the restricted time frame within which the research had to be completed. The questionnaires were emailed to the respondents and the participants were asked to fill in their responses in the online forms. The accomplished responses were then sent back by email. The online mode of participation in the primary data collection process has proven to be effective owing to its time saving feature and the ease by which the participants filled up their responses at their convenience.

The questionnaire comprised of nine questions that focused on gaining evidence for the possibilities of integrating the two systems and the envisaged benefits to business growth and productivity:

Q1: Do you think that Lean can add value to EMS systems? If yes, how?

Q2: Do you feel that Lean and EMS can be integrated to provide businesses with improved performance and enhanced productivity?

Q3: What according to you are the primary benefits of using the Lean and EMS systems within the business?

Q4: Identify some of the pertinent issues and challenges facing effective application of these systems within the organisation?

Q5: What measures according to you can be taken to overcome such issues for effective implementation of these two systems?

Q6: What according to you are the primary objectives that emphasize the need for an integrated business model? 
Am. J. Applied Sci., 8 (11): 1182-1194, 2011

Table 1: The research findings for an improved understanding of the evidence collected

\begin{tabular}{ll}
\hline Questions & Respondent briefings \\
\hline Can Lean add value to EMS systems? & $98 \%$ of the respondents felt that Lean can add value to EMS systems \\
Lean and EMS integration for improved productivity & $97 \%$ felt that Lean EMS integration can enhance productivity and performance \\
Primary benefits of using the Lean and EMS systems & $\begin{array}{l}\text { Sustainable growth and development combined with improved productivity and } \\
\text { streamlined work process }\end{array}$ \\
& $\begin{array}{l}\text { Lack of adequate leadership and managerial support for effective implementation } \\
\text { participative leadership approach, employee }\end{array}$ \\
Issues and challenges facing effective application & empowerment and adequate resource mobilization \\
Strategies for overcoming such issues & Sustainable development, minimized waste and \\
for effective implementation & cost savings in operations \\
Primary objectives that emphasize the need & $98 \%$ felt positive \\
for an integrated business model & Structured approach to change management, training of employees, participative \\
Can integrated models contribute to business efficiencies & decision making and enabling organisational structure that supports reduced \\
Parameters that can facilitate such frameworks & hierarchical levels \\
& Constant monitoring of work processes, identifying loopholes \\
How can effectiveness of such models be measured in & in the system, adopting innovative approach to work and technology developments \\
terms of business growth and sustainable development
\end{tabular}

Q7: Do you think that an integrated model can contribute to business efficiencies in practical scenarios?

Q8: If yes, what are the parameters that can facilitate such frameworks?

Q9: How can the effectiveness of such models are measured in terms of business growth and sustainable development?

Research limitations: The research study was limited in its scope in terms of the small size of the sampling unit. The 15 respondents were not enough to provide a collective view of the practical insights associated with the use of Lean and EMS systems. However, the study served to provide vital data related to practical benefits and challenges facing the application of the systems. The findings of the research process are outlined and presented in a structured format in the results and analysis of this report.

Research findings: The research findings Table 1 provides an overview of the responses of the participants to the questionnaire given to them. The opinions and information provided by the respondents provided a base for further analysis and discussion on the research study.

\section{RESULTS AND DISCUSSION}

Can Lean add value to EMS? In response to the first question all the respondents felt that Lean can add extensive value to the EMS by eliminating non-value addition processes and adopting tactical methods of eliminating waste. These involve the use of popular Lean methods such as Kaizen, Just in Time (JIT) and Total Productive Maintenance (TPM). The findings strongly emphasize that an organisation pursuing Lean principles can effectively reduce costs of operation, enhance quality standards and respond to customer needs that translate to improved business performance. The application of EMS with Lean can help organisations in identifying potential waste in areas of manufacturing or resource allocation that can help in creating an optimised production system that is highly efficient and productive.

Lean-EMS integration: A majority of the respondents felt that the integration of Lean and EMS can result in highly efficient and effective systems that focus on value addition strategies. The effectiveness of integrating the two systems can be realized by adopting processes and procedures designed to eliminate waste and create an economically sustainable work environment. This can help organisations in optimising production costs and meeting organisational goals and targets through a continual improvement process that reviews existing practices and recommends enhanced procedures to drive competitive growth in industry.

Benefits of Lean-EMS integration: The benefits of integrating Lean-EMS systems were widely appreciated by all respondents who felt that each of the systems individually served to enhance the production processes within the organisation. The goals of each system may be distinct in terms of their contribution to the environmental objectives and optimised production processes. Hence an integration of both the systems can enable organisations to achieve environmental objectives, safety conditions and profitability of business by the streamlining of work processes.

Issues and challenges facing Lean-EMS integration: Lean and EMS integration requires planned coordination and strategic implementation methods to in order to be effective, according to a majority of the respondents. The major challenges facing an effective integration according to the findings of the primary 
Am. J. Applied Sci., 8 (11): 1182-1194, 2011

research study were identified as lack of managerial capabilities within organisations to lead the changes within the existing system. Change management requires able and effective leadership, focused planning, forecasting and implementing strategic moves for realizing the true potentials of the integrated approach. Managerial and leadership capabilities who understand the essentials of the principles and practices related to Lean and EMS.

Overcoming issues and challenges to effective LEAN-EMS integration: The respondents felt that the potential challenges and issues facing effective LEANEMS integration can be overcome by adopting a wellconsidered implementation strategy and change management principles. This requires creating an awareness of the integrative approach and its benefits among the workforce, emphasizing the benefits of the proposed changes, training the workforce on the proposed systems and ensuring employee participation in driving the change objectives.

The findings of the primary research process draw the significance and potentials of integrating LEANEMS systems for building an efficient organization. The effectiveness of such systems is widely influenced by management practices that drive organizational commitment to international standards of quality and optimized production capabilities.

Conceptual framework and business model: The subsequent discussion focuses on the management systems that can be adopted towards an effective LeanEMS integration for enhanced efficiency in operations. The study has highlighted the significance of LeanEMS systems within the organisational environment and its contribution to meeting organisational goals and creating a sustainable business model. Based on the primary and secondary research findings, a conceptual framework is proposed by the researcher that takes into account the goals of sustainable business growth and development.

The framework proposed here places emphasis on the need for providing an environment-friendly workplace, adequate health and safety standards for employees as well as a cost-efficient operational process for enhanced productivity and performance. The Fig. 1 representation of the business model below illustrates the approach that can be adopted for improved business performance and operational efficiencies:

The proposed framework requires the organisations to identify the various parameters that have a direct or indirect impact on the environmental aspects and operational efficiency. These parameters include employee health, work safety, environmental pollution, stakeholders' needs, operational bottlenecks and operational procedures that contribute to wastage in any form. The identification of these parameters equips the organisation with the vital information based on which the management can define the organisational goals and objectives for the proposed changes within the work culture. Once the management identifies the problems and areas of development within the existing work processes, the next step involves the defining of corporate vision that supports organisational goal for sustainable growth and development. Strong strategies are the supporting pillars for the implementation of a new work process accompanied by changes within organisational structure to facilitate an innovative work culture. The final step involves the evaluation of strategic implementations and changes through an assessment of the observed impacts on operational efficiency. This process requires constant supervision and monitoring for effective results.

Novelty of the framework: The proposed model is adapted from the theoretical framework of Hoshin Planning that was developed for the purpose of guiding business processes towards enhanced results. The Hoshin framework Fig. 2 enables organizations to identify critical areas of change and innovation for enhanced business results, determine the strategic plans that can help the organization in accomplishing the defined vision and providing a mechanism for reviewing and assessing the implemented changes for evaluating business decisions (Cowley and Domb, 1997). "The basic premise of Hoshin is that the organization will identify an area or two each year for special focus and will seek a major improvement in it" (Cowley and Domb, 1997).

The proposed LEAN-EMS model has been adapted from the Hoshin framework that provides the essential direction towards the planning and the implementation of an efficient integrated business model. The novelty of the framework lies in its focus on creating a strong corporate vision and emphasis on enabling a strengthened culture that is based on employee awareness of the proposed objectives and its feasibility. The entire framework provides the organizations with a structured application model that can help the managers in identifying the potential challenges and issues facing the effective implementation business principles based on integrated LEAN and EMS framework. The distinctive aspect of the proposed framework lies in its scope of identifying operational loopholes and environmental concerns that underlines the significance of implementing an integrated approach. 


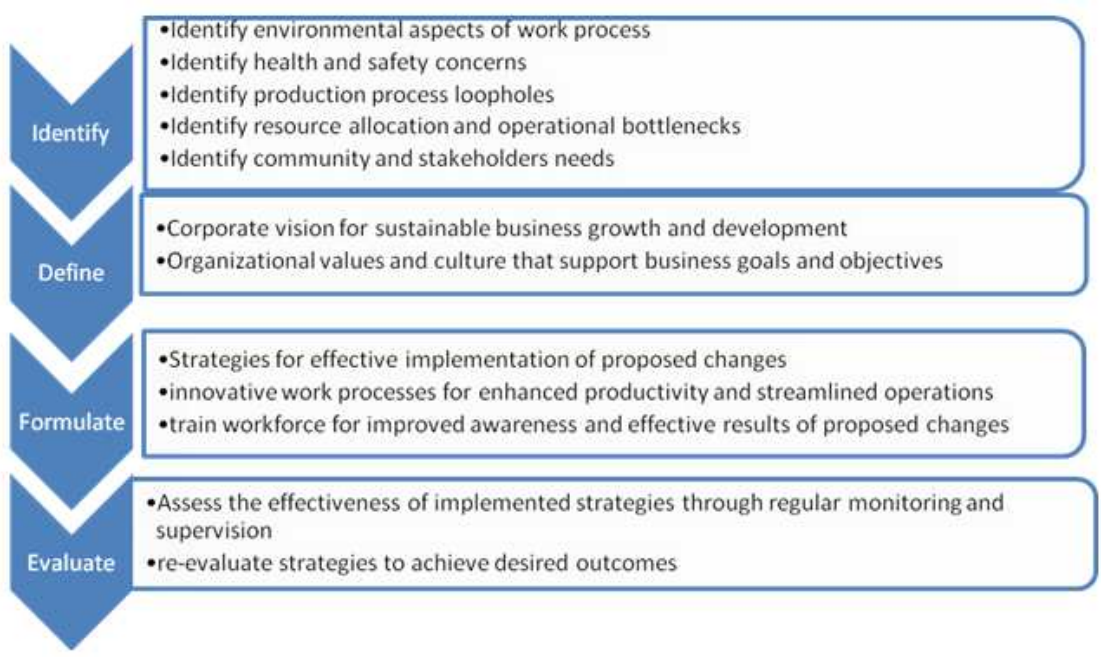

Fig. 1: Integrated Business Model

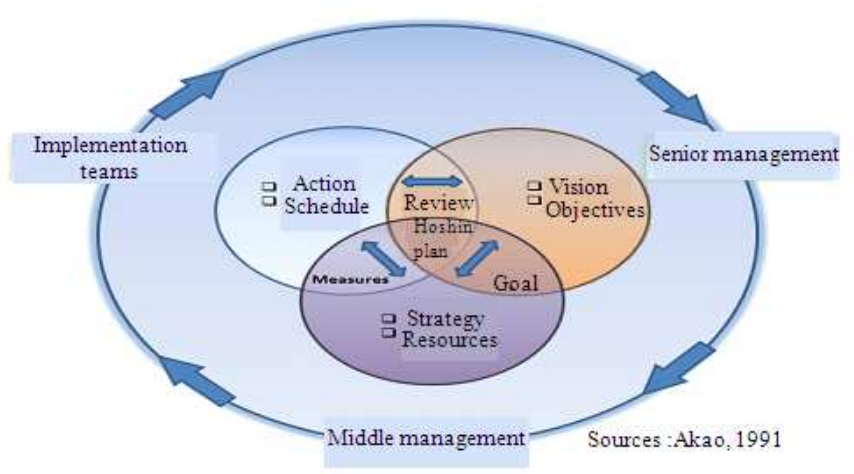

Fig. 2: An overview of Hoshin Planning framework (Source: Akao, 2004)

Implementation plan for the proposed framework: The implementation plan for the proposed conceptual framework focuses on collaborating management efforts and strategies towards the desired organizational goals and objectives. The Fig. 3 provides the implementation plan for the framework.

Each stage of the implementation schedule must be evaluated through a process of constant feedback and discussions with employees for desired results. Preformatted feedback forms are a useful tool to gain insights into employee opinion and assess the effectiveness of each change mechanism pursued. One of the key aspects determining the success of implementation efforts lies in the ability of the management to communicate its vision and persuade a change mechanism that focuses on gaining employee participation to the proposed changes. Hence the implementation plans is developed around building a strong vision for the workforce and elaborate training programs that create an awareness of the need for the proposed changes, the change initiatives and the potential implications on different work processes and departments. The training workshops will focus on improving employee involvement and participation in the change program through feedbacks, open discussions and presentations that will illustrate the scope of the desired changes and its implications.

Communication is yet another vital aspect influencing the success of the proposed business model since it impacts the organizational culture and its flexibility to adapt to emerging business needs. Management focus on transparency of communication is critical for ensuring employee participation and acceptance to the proposed changes. Employee involvement initiatives can be effectively led by process improvement teams and feedback programs that elicit employee suggestion and observation. 


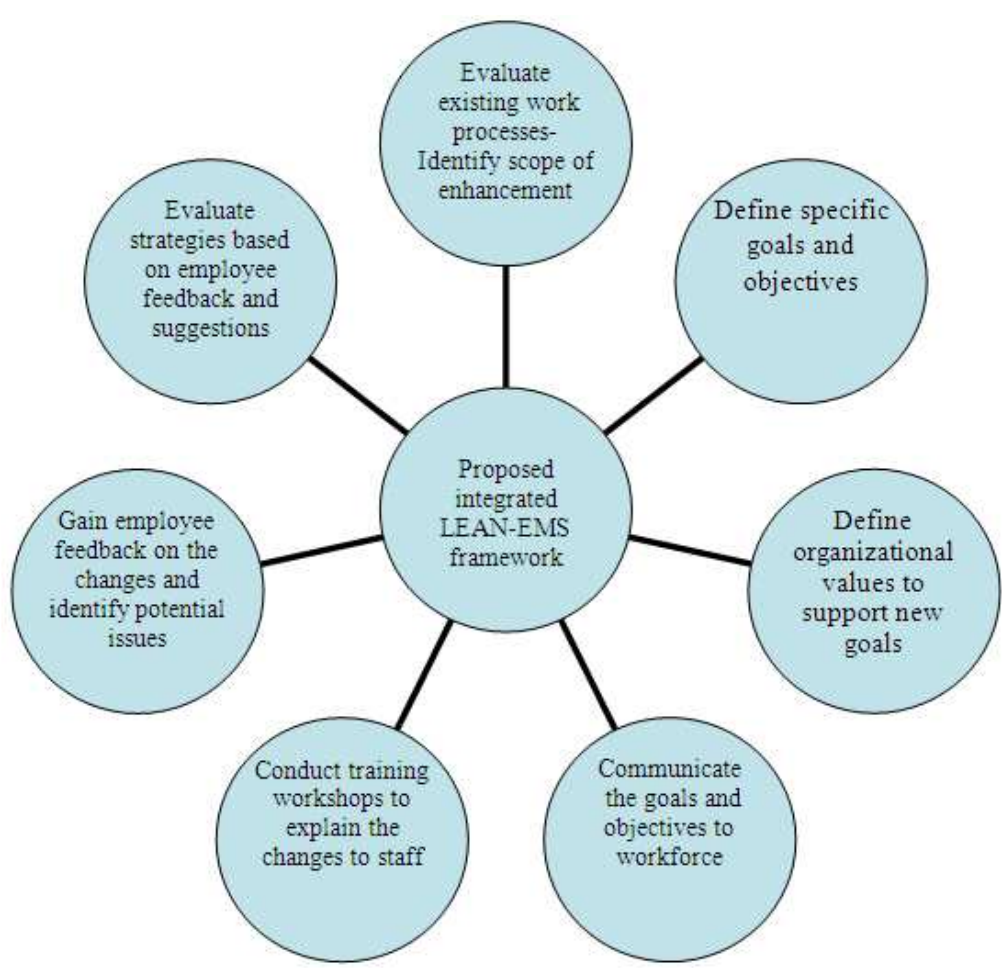

Fig. 3: Implementation plan for the framework

This requires able leadership and team work efforts that focuses on building a strong and unified organizational work culture. Assessment of employee performance through well defined performance indicators and evaluation procedures can help reinstate employee confidence and trust in managerial capabilities.

\section{CONCLUSION}

The integration of Lean and EMS can present increased challenges to the organisations in the form of implementation strategies, identification of the true potentials of the systems and the creation of awareness among the workforce on the changing practices and procedures at workplace. "If Lean manufacturing can serve as catalyst to Green manufacturing system implementation, then this relationship could have a profound effect on the means by which Green manufacturing systems are promoted by agencies such as the EPA" (Bergmiller and McCright, 2009). Research studies have focused on the collective benefits and operational efficiency that an integration of these two business principles can lend to organisations (Bergmiller and McCright, 2009).

The effective implementation of Lean systems within organisations depends to a large extent on the leadership capabilities within the organisation and employee involvement. Lean manufacturing methods are based on "specifying the value, identifying the value stream, flow, pull and perfection" (Bergmiller and McCright, 2009). Value in this context refers to the perception of goods and services by the customer. Analysis of the value stream or the customer value of specific goods and services can also help organisations in identifying the wasteful resources or processes adding to the production costs. This helps the organisations in meeting market demands without spending or wasting resources on extra production of goods and services.

The EMS functions on similar lines though the objectives are focused on meeting the international quality standards laid down by ISO Management Standards. The EMS principles and practices are based on the fact that organisations must review their operations at regular intervals to assess if the existing practices are contributing to organisational goals and complying with global standards of quality. "Though the EMSs of different organisations vary widely in details, all usually include an environmental policy statement: an initial review, environmental objectives and targets, implementation procedures, internal monitoring and auditing; and internal reporting" 
(OECD, 2001). Documentation of work procedures are effective means of implementing such standards and enabling effective monitoring of such systems.

The integrative approach business model has distinctive benefits since it lends the organisation with the capability to expand its operations through streamlining of processes and compliance with ISO standards. This can lead to effective business results as well as the creation of a sustainable organisation that is based on the proven management models of Lean and EMS. The research study has investigated the possibilities of exploiting the benefits of both the systems and adopting an effective business model that improves business efficiency and productivity. However, the potentials of Lean and EMS integration remain vastly unexplored since changes within the business environment and innovative technologies can widely impact operational processes and procedures. Future research studies can expand on the evolving technology implementation to provide improved models that can simplify work processes and develop new standards in waste management

\section{REFERENCES}

Akao, Y., 2004. Hoshin Kanri: Policy Deployment for Successful TQM. 1st Edn., Productivity Press, Cambridge MA., ISBN: 156327311X, pp: 244.

Bergmiller, G.G. and P.R. McCright, 2009. Parallel models for Lean and green operations. Proceedings of the 2009 Industrial Engineering Research Conference (IERC'09), USA., pp: 1-6.

Cheremisinoff, N.P., P. Rosenfeld and P.E. Rosenfeld, 2009. Handbook of Pollution Prevention and Cleaner Production Vol. 2: Best Practices in the Wood and Paper Industries. 1st Edn., William Andrew, Norwich, N.Y., ISBN: 008096446X, pp: 350.

Collin, R.M. and R.W. Collin, 2009. Encyclopedia of Sustainability: Environment and Ecology. ABCCLIO, Santa Barbara, ISBN: 0313352631, pp: 384.

Cowley, M. and E. Domb, 1997. Beyond Strategic Vision: Effective Corporate Action with Hoshin Planning. 1st Edn., Butterworth-Heinemann, Boston, ISBN: 0750698438, pp: 245.

Cragg, W., 2005. Ethics Codes, Corporations and the Challenge of Globalization. 1st Edn., Edward Elgar Publishing, Cheltenham, ISBN: 1845421027, pp: 396.

EPA, 2002. Practical Guide to Environmental Management for Small Business. 1st Edn., U.S. Environmental Protection Agency, Washington pp: 47.
Gbedemah, F.S., 2004. Environmental Management System (ISO 14001) Certification in manufacturing companies in Ghana: prospects and challenges. M.Sc. Thesis, Lund University.

Gordon, P.J., 2001. Lean and Green: Profit for your Workplace and the Environment. 1st Edn., BerrettKoehler Publishers, San Francisco, ISBN: 1576751708, pp: 218.

Haklik, J.E., 2002. ISO 14001 and sustainable development. Transformation Strategies.

Hancock, J., 2005. Investing in Corporate Social Responsibility: A Guide to Best Practice, Business Planning and The UK's Leading Companies. 1st Edn., Kogan Page Publisher, London, ISBN: 074944147X, pp: 359.

LEI, 2009a. What is lean. Lean Enterprise Institute.

LEI, 2009b. Principles of lean. Lean Enterprise Institute.

Lesourd, J.B. and S. Schilizzi, 2001. The Environment in Corporate Management: New Directions and Economic Insights. 1st Edn., Edward Elgar Publishing, Cheltenham, ISBN: 1843764539, pp: 400.

MacDonald, J.P., 2005. Strategic sustainable development ${ }^{1}$ using the ISO 14001 standard. J. Cleaner Product., 13: 631-643. DOI: 10.1016/J.JCLEPRO.2003.06.001

Malhotra, N.K. and D.F. Birks, 2007. Marketing Research: An Applied Approach. 3rd Edn., Pearson Education, Harlow, ISBN: 0273706896, pp: 835.

Maxwell, J.A., 2005. Qualitative Research Design: An Interactive Approach. 2nd Edn., Sage Publications, Thousand Oaks, CA., ISBN-10: 0761926089, pp: 174.

Miller, G., J. Pawloski and C.R. Stanridge, 2010. A case study of Lean, sustainable manufacturing. J. Indus. Eng. Manage., 3: 11-32. DOI: 10.3926/jiem.2010.v3n1.p11-32

Mitsuishi, M., K. Ueda and F. Kimura, 2008. Manufacturing Systems and Technologies for the New Frontier. 1st Edn., Springer, Guildford, ISBN: 1848002661 , pp: 556.

Murman, E.M., 2002. Lean Enterprise Value: Insights from MIT's Lean Aerospace Initiative. 1st Edn., Palgrave Macmillan, Basingstoke, ISBN: 1403907501 , pp: 344.

OECD, 2001. Corporate Responsibility: Private Initiatives and Public Goals. 1st Edn., OECD Publishing, Paris, ISBN-10: 9264186697, pp: 111.

Parto, S. and B. Herbert-Copley, 2007. Industrial Innovation and Environmental Regulation: Developing Workable Solutions. 1st Edn., IDRC, Ottawa, ISBN: 9280811274, pp: 305. 
Reidenbach, R.E. and R.W. Goeke, 2006. Value-Driven Channel Strategy: Extending the Lean Approach. 1st Edn., ASQ Quality Press, Milwaukee, ISBN: 0873896599, pp: 171.

RAESL, 2004. Findings and recommendations on lean production and environmental management systems in the shipbuilding and ship repair sector. Ross and Associates Environmental Consulting, Ltd.

Russell, R.S. and B.W. Taylor-lii, 2008. Operations Management Along the Supply Chain. 6th Edn., Wiley India Pvt. Ltd., India, ISBN-10: 8126518669, pp: 804.

Sarkar, D., 2008. Lean for Service Organizations and Offices. 1st Edn., Pearson Education India, India, ISBN: 8131725502, pp: 248.

Sedjo, R.A., A. Goetzl and S.O. Moffat, 1998. Sustainability of Temperate Forests. 1st Edn., Resources for the Future, Washington, DC., ISBN: 0915707985, pp: 102.
Turbide, D.A., 2005. Five ways ERP can help you implement Lean. Asia Pacific Food Industry, 18: 68-74.

Visser, W., D. Matten, M. Pohl and N. Tolhurst, 2010. The A to $\mathrm{Z}$ of Corporate Social Responsibility. 2nd Edn., John Wiley and Sons, Chichester, ISBN: 0470686502, pp: 500.

Whitelaw, K., 2004. ISO 14001 Environmental Systems Handbook. 2nd Edn., Elsevier/Butterworth Heinemann, Butterworth, ISBN: 0750648430, pp: 237.

Wilson, W.G. and D.R. Sasseville, 1998. Sustaining Environmental Management Success: Best Business Practices from Industry Leaders. 1st Edn., John Wiley and Sons, New York, ISBN: 047124645X, pp: 266.

Woodside, G. and P. Aurrichio, 2000. ISO 14001 Auditing Manual. 1st Edn., McGraw-Hill Professional, New York, ISBN-10: 0071349073, pp: 224. 